\title{
PENGARUH KESELAMATAN DAN KESEHATAN KERJA TERHADAP KINERJA PEGAWAI APARATUR SIPIL NEGARA PADA DINAS PEMADAM KEBAKARAN KABUPATEN BONE
}

Edi Jusriadi

edijusriadi@gmail.com

Fakultas Ekonomi dan Bisnis

Universitas Muhammadiyah Makassar

Asmina

asmina@unismuh.ac.id

Fakultas Ekonomi dan Bisnis

Universitas Muhammadiyah Makassar

\begin{abstract}
The research method uses quantitative methods with data collection techniques using questionnaires which were distributed to 57 respondents. Data analysis techniques used in this study are multiple linear regression with work safety variables (X1), health variables (X2) and the performance of the State Civil Apparatus (Y). The results showed that work safety variables had a positive and significant effect on the performance of the State Civil Apparatus in the Bone Fire Service with $t$ count 3.828> $t$ table 2.002 with a significance level of $0.000<0.005$, the effect of occupational health had a positive but not significant effect with a t value of $1.667<t$ table 2,002 with a significance level of 0.099>0.05.
\end{abstract}

Keywords: Work Safety, Work Safety and Employee Performance

\begin{abstract}
Abstrak
Metode penelitian menggunakan metode kuantitatif dengan teknik pengumpulan data menggunakan kuesioneryang dibagikan kepada 57 responden. Teknik analisis data yang digunakan dalam penelitian ini adalah regresi linier berganda dengan variabel keselamatan kerja $\left(\mathrm{X}_{1}\right)$, variabel kesehatan $\left(\mathrm{X}_{2}\right)$ dan kinerja Aparatur Sipil Negara (Y). Hasil penelitian menunjukkan variabel keselamatan kerja berpengaruh positif dan signifikan terhadap kinerja Aparatur Sipil Negara pada Dinas Pemadam Kebakaran Kabupaten Bone dengan nilai t hitung 3,828 > t tabel 2,002 dengan taraf signifikasi $0,000<0,005$, pengaruh kesehatan kerja berpengaruh positif tetapi tidak signifikan dengan nilai t hitung 1,667< tabel 2,002 dengan taraf signifikasi 0,099 >0,05.
\end{abstract}

Kata Kunci : Keselamatan Kerja, Kesehatan Kerja dan Kinerja Pegawai 


\section{PENDAHULUAN}

Bercermin pada beberapa masalah yang terjadi di perusahaan kurangnya kesadaran akan pentingnya program kesehatan dan keselamatan kerja menjadi pokok persoalan utama yang harus di selesaikan. Seharusnya manajer perusahaan perlu memberikan perhatian yang sungguh-sungguh terhadap pentingnya pemahaman serta program pelaksanaan keselamatan dan kesehatan kerja dalam organisasi perusahaan. Ada berbagai perusahaan/instansi dari berbagai sektor yang telah menerapkan keselamatan dan kesehatan kerja, salah satunya yaitu Dinas Pemadam Kebakaran di Kabupaten Bone, yang merupakan instansi yang bergerak di bidang Sosial dan memiliki resiko pekerjaan yang tinggi sehingga perlu menghindari terjadinya kecelakaan dan penyakit akibat kerja. Dengan diterapkannya program keselamatan dan kesehatan kerja maka, akan menciptakan hasil kerja yang lebih optimal dan mampu memberikan perasaan nyaman, aman, dan sehat kepada para pekerja.

Berdasarkan informasi yang diperoleh dari salah satu pegawai Aparatur Sipil Negara, terdapat banyak fakta mengenai terjadinya kecelakaan kerja pada Dinas Pemadam Kebakaran di Kabupaten Bone. Baik kecelakaan tunggal maupun kecelakaan kelompok adapun kecelakaan yang pernah terjadi, yaitu kecelakaan saat berkendara (pada saat perjalanan menuju lokasi kebakaran), serta kecelakaan tunggal berupa peledakan yang mengakibatkan pekerjanya mendapat luka bakar di bagian kepala, dan bagian tubuh lainnya, adapun terkena ujung seng yang panas pada bagian tangan dan masih banyak kecelakaan lainnya yang mendapatkan perawatan khusus di Rumah Sakit
Pancaitana kabupaten Bone, sehingga banyak pihak yang dirugikan. Akibat kecelakaan yang terjadi menyebabkan menurunnya tingkat kinerja pegawai, karena atas insiden tersebut Pegawai Aparatur Sipil Negara banyak yang sakit sehingga kehadirannya tidak mencapai target, sehingga kuantitas dan kualitas pekerjaan mereka hasilkan pun menurun. Upaya yang dilakukan adalah perlunya perhatian khusus pada program keselamatan dan kesehatan kerja pada Dinas Pemadam Kebakaran di Kabupaten Bone.

Berdasarkan uraian di atas, maka penulis tertarik untuk melakukan penelitian dengan judul "Pengaruh Keselamatan dan Kesehatan Kerja terhadap Kinerja Aparatur Sipil Negara pada Dinas Pemadam Kebakaran Kabupaten Bone"

\section{TINJAUAN PUSTAKA}

\section{a. Pengertian kinerja}

Menurut Mathis dan jackson (2006:65) menyatakan bahwa kinerja pada dasarnya adalah apa yang dilakukan atau tidak dilakukan pegawai. Manajemen kinerja adalah keseluruhan kegiatan yang dilakukan untuk meningkatkan kinerja perusahaan atau organisasi. Manajemen Pegawai Negeri Sipil Harun Samsuddin (2018:3) adalah pengelolaan negeri sipil untuk menghasilkan pegawai negeri sipil yang profesional, memiliki nilai dasar, etika profesi, bebas dari intervensi politik, bersih dari praktik korupsi, kolusi, dan nepotisme (pasal 1 pp no. 11 tahun 2017).

Menurut Fuad Mas'ud (2004:50) menyatakan ada lima indikator kinerja pegawai secara individu, yang dapat dijelaskan sebagai berikut :

1) Kualitas

Tingkat dimana hasil aktivitas yang dilakukan mendekati sempurna dalam 
arti menyesuaikan beberapa cara ideal dari penampilan aktivitas maupun memenuhi tujuan yang diharapkan dari suatu aktivitas.

2) Kuantitas

Jumlah yang dihasilkan dinyatakan dalam istilah sejumlah unit, jumlah siklus aktivitas yang diselesaikan.

\section{3) Ketepatan Waktu}

Tingkat suatu aktivitas diselesaikan pada waktu awal yang diinginkan dilihat dari sudut koordinasi dengan hasil output serta memaksimalkan waktu yang tersedia untuk aktivitas orang lain.

4) Efektivitas

Tingkat pengguna sumber daya manusia dalam organisasi dengan maksud menaikkan keuntungan atau mengurangi kerugian dari setiap unit dalam pengguna sumber daya manusia.

5) Komitmen Kerja

Tingkat dimana karyawan mempunyai komitmen kerja dengan perusahaan dan tanggung jawab kepada perusahaan.

\section{METODE PENELITIAN}

\section{a. Jenis dan Pendekatan Penelitian}

Berdasarkan variabel-variabel yang di teliti jenis penelitian yang digunakan yaitu penelitian kuantitatif. Metode ini di sebut metode ilmiah karena telah memenuhi kaidah-kaidah ilmiah yaitu, empiris, obyektif, terukur, rasional, dan sistematis. Metode ini disebut metode kuantitatif karena data penelitian berupa angka-angka. Sedangkan pendekatan penelitian menggunakan metode survei yaitu teknik pengumpulan informasi yang dilakukan dengan cara menyususn daftar pertanyaan yang diajukan pada responden dalam bentuk sampel dari sebuah populasi. (Sugiyono, 2014:7).

\section{b. Lokasi dan Waktu Penelitian}

Lokasi penelitian merupakan suatu tempat atau wilayah dimana penelitian tersebut akan dilakukan oleh penulis untuk mengambil penelitian dengan mengambil objek penelitian pada Dinas Pemadam Kebakaran di Kabupaten Bone. Adapun waktu yang digunakan dalam penelitian ini akan dilakukan di bulan Mei sampai Juni 2019.

\section{c. Definisi Operasional Variabel dan pengukuran}

Peneliti memberikan persamaan peresepsi kepada pembaca, maka diberikan batasan-batasan terhadap variabel-variabel yang di teliti.

1) Keselamatan kerja merupakan kondisi aman atau selamat dari penderitaan, kerusakan dan kerugian dari tempat kerja berupa mesin dan peralatan, lingkungan kerja dan metode kerja, Indikatornya yaitu metode kerja, lingkungan kerja dan mesin dan peralatan.

2) Kesehatan kerja merupakan suatu kondisi yang bebas dari gangguan secara fisik dan psikis, penyakit akibat kerja yang di sebabkan oleh lingkungan kerja yaitu indikatornya lingkungan kerja, kesehatan tenaga kerja, dan memeliharaan kesehatan.

3) Kinerja pegawai adalah hasil kerja yang dapat dicapai oleh seseorang atau kelompok orang dalam suatu organisasi sesuai dengan wewenang dan tanggung jawab masing-masing dalam rangka upaya mencapai tujuan organisasi bersangkutan secara legal tidak melanggar hukum dan sesuai dengan moral yaitu ndikatornya kualitas, kuantitas, ketepatan waktu, efektiviyas dan komitmen kerja

Penelitian ini akan menggunakan skala Likert. Skala Likert di gunakan untuk 
mengukur sikap, pendapat, dan presepsi seseorang atau sekelompok tentang kejadian atau gejala sosial. Penggunaan angket di harapkan akan memudahkan bagi responden dalam memberikan jawaban karena alternatif jawaban telah tersedia, sehingga untuk menjawabnya hanya perlu waktu singkat. Pada setiap item soal disediakan 5 pilihan jawaban dengan skor nilai masing-masing sebagai berikut:

\begin{tabular}{||l||c||c||}
\hline 1. & $\begin{array}{c}\text { Sangat tidak setuju } \\
\text { (STS) }\end{array}$ & 1 \\
\hline \hline 2. & Tidak setuju (TS) & 2 \\
\hline \hline 3. & Kurang setuju (KS) & 3 \\
\hline \hline 4. & Setuju (S) & 4 \\
\hline \hline 5. & Sangat setuju (SS) & 5 \\
\hline
\end{tabular}

\section{d. Populasi dan Sampel}

1) Populasi

Populasi penelitian atau objek penelitian yang diambil oleh peneliti yaitu seluruh Aparatur Sipil negara pada Dinas Pemadam Kebakaran Kabupaten Bone yang berjumlah 130 Aparatur Sipil Negara. Adapun responden yang dipengaruhi yaitu teknik sensus, menurut Sugiyono, (2014:80) populasi adalah wilayah generalisasi yang terdiri atas objek atau subjek yang memiliki kualitas dan karakteristik tertentu yang ditetapkan oleh penelitian untuk dipelajari dan kemudian disimpulkan.

2) Sampel Penelitian

Sampel adalah bagian dari jumlah dan karakteristik yang dimiliki oleh populasi tersebut. Sugiyono (2014:93) sedangkan pada literatur lain sampel adalah bagian atau wakil populasi yang diteliti. Dimana penelitian sampel apabila kita bermaksud untuk menggeneralisasikan hasil penelitian sampel. Cara menentukan jumlah sampel dalam penelitian ini adalah menggunakan rumus Slovin sebagai berikut:

$\mathrm{N}$

$$
\mathrm{N}=1+\mathrm{N}(\mathrm{e})^{2}
$$

\section{Keterangan:}

$\mathrm{n}$ : ukuran sampel

$\mathrm{N}$ : ukuran populasi (130)

e : tingkat kesalahan pengambilan sampel $(10 \%)$

$\mathrm{N}$

$\mathrm{N}=$

$$
\begin{array}{r}
1+\mathrm{N}(\mathrm{e})^{2} \\
130
\end{array}
$$

$\mathrm{N}=$

$$
1+130(0.1)^{2}
$$

\section{0}

$\mathrm{N}=$

$$
=56,52
$$

Dibulatkan menjadi 57 orang. 2,3

\section{e. Metode Pengumpulan Data}

Metode pengambilan data yang di gunakan dalam penelitian ini adalah sebagai berikut :

1) Observasi adalah pengamatan atau peninjauan secara mendalam. Apabila dihubungkan dengan penelitian maka observasi dapat diartikan sebagai salah satu teknik pengumpulan data dengan menangadakan pengamatan secara langsung terhadap sesuatu baik benda, perilaku, maupun kondisi dari berbagai gejala yang di teliti. Observasi di lakukan dengan cara mendatangi lokasi penelitian yang terdapat pada kabupaten bone tepatnya pada Dinas Kebakaran Kabupaten Bone.

2) Kuesioner adalah teknik pengumpulan data yang di lakukan dengan cara memberi seperangkat 
pertanyaan/pernyataan kepada responden untuk di jawab agar memperoleh informasi yang di butuhkan.

3) Dokumentasi, yaitu dengan melakukan pengumpulan dan mempelajari dokumen-dokumen pendukung yang di peroleh secara langsung dari Dinas Pemadam Kebakaran di Kabupaten Bone, seperti sejarah singkat berdirinya perusahaan,struktur organisasi perusahaan dan dokumendokumen pendukung lainnya.

\section{f. Teknik Analisis}

1) Instrumen Penelitian

a) Uji validitas

Uji validitas untuk mengetahui kelayakan butir-butir dalam suatu daftar (konstruk) pertanyaan dalam mendefinisikan variabel. Menilai masingmasing butir pertanyaan dapat di nilai dari nilai corrected item-total correlation. Suatu butir pertanyaan dikatakan valid jika nilai r-hitung yang merupakan nilai dari Corrected Item-Total Correlation , dari r-tabel yang di peroleh melelui Df (Degree Of Freedom). Untuk menguji valid tidaknya pertanyaan dapat di lakukan melalui program komputer Excel Statistic Analisis \& SPSS 22.

b) Uji Realibilitas

Reliabilitas merupakan ukuran suatu kestabilan dan konsistensi responden dalam menjawab hal yang berkaitaan dengan konstruk-konstruk pertanyaan yang merupakan dimensi suatu variabel dan di susun dalam suatu bentuk kuesioner. Alat ukur yang akan di gunakan adalah cronbach alpha melalui program komputer excel statistic analysis \& spss 22. Reliabilitas suatu konstruk variabel dikatakan baik jika memiliki nilai cronbach alpha > 0,60.

2) Analisis regresi linier berganda.
Analisis ini (Sugiyono 2014:147) di gunakan untuk mengetahui apakah ada pengaruh positif dari variabel independen $\left(\mathrm{X}_{1}\right.$, dan $\left.\mathrm{X}_{2}\right)$ terhadap variabel dependen $(\mathrm{Y})$ dengan model regresi sebagai berikut: 1

$$
\mathbf{Y}=\boldsymbol{\beta} \mathbf{o}+\boldsymbol{\beta}_{1} \mathbf{X}_{1}+\boldsymbol{\beta}_{2} \mathbf{X}_{2}+\mathbf{e}
$$

Keterangan:

$$
\begin{array}{ll}
\mathrm{Y} & =\text { Kinerja ASN } \\
\beta_{0} & =\text { Konstanta } \\
\beta_{1} \beta_{2} & =\text { Koefisien regresi } \\
\mathrm{e} & =\text { Standart error } \\
\mathrm{X}_{1} & =\text { Keselamatan kerja } \\
\mathrm{X}_{2} & =\text { Kesehatan kerja }
\end{array}
$$

\section{HASIL DAN PEMBAHASAN}

\section{a. Hasil Penelitian}

1. Karakteristik Responden

Gambaran umum responden ini bertujuan untuk mengetahui karakteristik dari pegawai yang terpilih menjadi responden. Penggolongan responden didasarkan pada jenis kelamin, usia dan tingkat pendidikan. Berdasarkan hasil penelitian yang telah dilaksanakan pada Dinas Pemadam Kebakaran Kabupaten Bone terhadap 57 responden melalui penyebaran kuesioner, maka karakteristik responden dapat digambarkan sebagai berikut :

a. Karakteristik reaponden berdasarkan jenis kelamin.

Analisis terhadap responden menurut jenis kelamin dilakukan untuk mengetahui proporsi jenis kelamin responden agar tidak terjadi pembedaan jenis kelamin dalam mengambil sampel. Berikut adalah komposisi jenis kelamin responden dalam tabel berikut : 
Tabel 4.1

Karakteristik Responden Berdasarkan Jenis Kelamin

\begin{tabular}{|l|l||c||c||}
\hline No & Jenis Kelamin & Jumlah & Persentase \\
\hline \hline 1. & Pria & 50 & $87,7 \%$ \\
\hline \hline 2. & Wanita & 7 & $12,3 \%$ \\
\hline \hline & Total & 57 & $100 \%$ \\
\hline
\end{tabular}

Sumber : Hasil Kuesioner Responden, 2019

\section{Berdasarkan}

tabel

menunjukkan bahwa pada penelitian ini didominasi oleh responden berjenis kelamin pria yaitu sebesar 87,7\% sedangkan yang berjenis kelamin wanita hanya sebesar $12,3 \%$.

b. Karakteristik Responden Berdasarkan Tingkat Pendidikan.

Analisis terhadap pendidikan dimaksudkan untuk mengetahui komposisi pendidikan responden. Berikut komposisi pendidikan responden dalam tabel berikut ini :

\section{Tabel 4.2}

Karakteristik Responden Berdasarkan Tingkat Pendidikan

\begin{tabular}{||l||l||c|c||}
\hline No & Pendidikan & Jumlah & Persentase \\
\hline \hline 1. & SMA & 27 & $47,4 \%$ \\
\hline \hline 2. & S1 & 21 & $36,8 \%$ \\
\hline \hline 3. & S2 & 9 & $15,8 \%$ \\
\hline \hline Total & & 57 & $100 \%$ \\
\hline \multicolumn{2}{|c|}{ Sumber : Hasil pengolahan } \\
\hline
\end{tabular}

kuesioner, 2019

Berdasarkan tabel menunjukkan bahwa sebagian besar responden memiliki latar belakang pendidikan tamatan sekolah menengah akhir yaitu sebesar $47,4 \%$ atau sebanyak 27 orang, responden yang berpendidikan S1 sebesar $36,8 \%$ atau sebanyak 21 orang, responden yang berpendidikan S2 sebesar 15,8\% atau sebanyak 9 orang.

c. Karakteristik Responden Berdasarkan Usia

Analisis terhadap umur, dimaksudkan untuk mengetahui komposisi umur responden. Berikut ini disajikan komposisi responden berdasarkan umur pada tabel berikut ini :

Tabel 4.3

Karakteristik Responden Bedasarkan Usia

\begin{tabular}{|l|l|c|c|}
\hline No & Usia & Jumlah & Persentase \\
\hline \hline 1. & $<30$ Tahun & 28 & $49,1 \%$ \\
\hline \hline 2. & 31-40 Tahun & 17 & $29,9 \%$ \\
\hline \hline 3. & 41-50 Tahun & 8 & $14, \%$ \\
\hline \hline 4. & $>50$ Tahun & 4 & $7, \%$ \\
\hline \multicolumn{2}{|l|}{ Total } & 57 & $100 \%$ \\
\hline
\end{tabular}

Sumber : Hasil Kuesioner Responden

Berdasarkan tabel 4.3 diatas menunjukkan bahwa responden didominasi oleh pegawai yang berusia $<30$ tahun yaitu sebesar 49,1\% atau sebanyak 28 orang, responden yang berusia 31-40 tahun sebesar 29,9\% atau sebanyak 17 orang, responden yang berusia $41-50$ tahun sebesar $14 \%$ atau sebanyak 8 orang sedangkan responden yang berusia $>50$ tahun sebesar $7 \%$ atau sebanyak 4 orang.

\section{Deskipsi Variabel Penelitian}

Berikut ini akan dijelaskan tentang item-item penelitian yang terdiri dari variabel keselamatan kerja $\left(\mathrm{X}_{1}\right)$, kesehatan kerja $\left(\mathrm{X}_{2}\right)$ dan kinerja pegawai (Y).Variabel Keselamatan Kerja (X $\left.X_{1}\right)$ Variabel keselamatan kerja $\left(\mathrm{X}_{1}\right)$ terdiri dari 3 item yaitu, instansi memberikan metode kerja yang baik terhadap pegawai agar sesuai dengan standar keaman agar menghindar tejadinya kecelakaan kerja $\left(\mathrm{X}_{1.1}\right)$, lingkungan kerja yang aman dapat mengurangi tingkat risiko kecelakaan kerja (X1.2), dan kondisi mesin yang baik dapat menghindari terjadinya kecelakaan 
kerja pada saat melaksanakan pekerjaan (X1.3).

Tabel 4.4

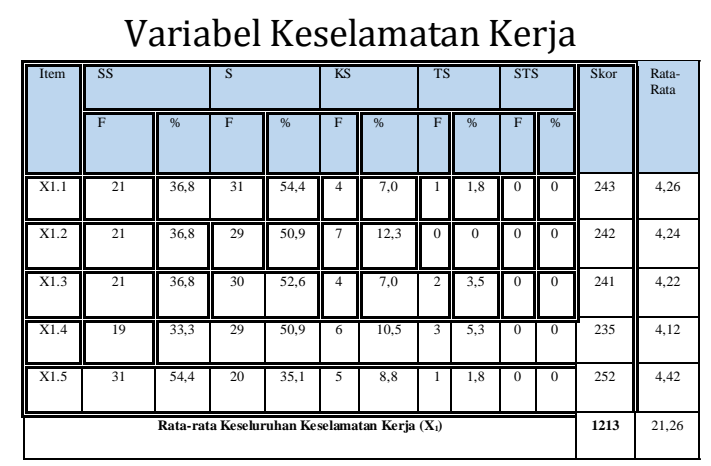

Sumber : Hasil Output SPSS 20, 2019

Berdasarkan tabel 4.4 menunjukan sebagian besar responden memilih jawaban sangat setuju yaitu sebesar 31 orang responden. Adanya data ini menunjukkan bahwa sebagian besar pegawai pada Dinas Pemadam Kebakaran Kabupaten Bone menyetujui bahwa penguasaan alat dan penggunaan atribut sefti K3 sangat menolong dan membantu dalam menghindari terjadinya kecelakaan kerja.

\section{a. Variabel Kesehatan Kerja}

Variabel kesehatan kerja (X2) terdiri dari 3 item yaitu lingkungan kerja yang bersih dapat menjaga kesehatan para pegawai selama bekerja (X2.1), perusahaan menyediakan penanganan gangguan kesehatan untuk pertolongan pertama bagi pegawai yang mendapat gangguan kesehatan (X1.2), dan perusahaanmenyediak obat-obatan dan memberikan jaminan kesehatan kepada pegawai setiap pegawai yang mendapat gangguan kesehatan (X1.2).
Tabel 4.5

Variabel Kesehatan Kerja

\begin{tabular}{|c|c|c|c|c|c|c|c|c|c|c|c|c|}
\hline \multirow{2}{*}{$\begin{array}{l}\text { Ite } \\
\text { m }\end{array}$} & \multicolumn{2}{|l|}{$\overline{S S S}$} & \multicolumn{2}{|l|}{$\mathrm{S}$} & \multicolumn{2}{|c|}{$\overline{\overline{\mathrm{KS}}}$} & \multicolumn{2}{|l|}{ 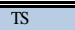 } & \multicolumn{2}{|c|}{ STS } & \multirow{2}{*}{$\begin{array}{l}\text { Sk } \\
\text { or }\end{array}$} & \multirow{2}{*}{$\begin{array}{l}\text { Rata- } \\
\text { Rata }\end{array}$} \\
\hline & $\bar{F}$ & $\overline{\%}$ & $\bar{F}$ & $\%$ & $\bar{F}$ & 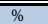 & FF & $\%$ & $\overline{F F}$ & $\%$ & & \\
\hline $\begin{array}{c}\mathrm{X} 2 . \\
1\end{array}$ & 21 & 36,8 & 288 & 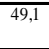 & 76 & 10,5 & 2 & $\begin{array}{l}3, \\
5\end{array}$ & \begin{tabular}{|l|l|l}
0 \\
\end{tabular} & 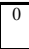 & $\begin{array}{c}23 \\
9\end{array}$ & 4,19 \\
\hline $\begin{array}{c}\mathrm{X} 2 . \\
2\end{array}$ & 25 & $\overline{43,9}$ & $\overline{299}$ & 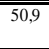 & 3 & 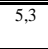 & 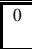 & $\overline{\overline{0}}$ & 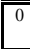 & 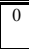 & $\begin{array}{r}25 \\
0\end{array}$ & 4,38 \\
\hline $\begin{array}{c}\mathrm{X} 2 . \\
3\end{array}$ & 24 & 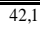 & 25 & 443,9 & $\overline{5}$ & \begin{tabular}{|l|l}
8,8 \\
\end{tabular} & 3 & $\begin{array}{l}5, \\
3\end{array}$ & 0 & 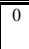 & $\begin{array}{c}24 \\
1\end{array}$ & 4,22 \\
\hline $\begin{array}{c}\mathrm{X} 2 . \\
4 \\
\end{array}$ & 25 & 433,9 & $\begin{array}{l}27 \\
\end{array}$ & $\begin{array}{l}47,4 \\
\end{array}$ & 5 & \begin{tabular}{|l|l}
8,8 \\
\end{tabular} & $\overline{\mid 00}$ & $\overline{00}$ & 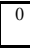 & $\overline{00}$ & $\begin{array}{c}24 \\
8 \\
\end{array}$ & 4,35 \\
\hline $\begin{array}{c}\mathrm{X} 2 . \\
5\end{array}$ & 21 & 36,8 & 29 & \begin{tabular}{c|c|}
50,9 \\
\end{tabular} & 7 & 12,3 & 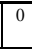 & $\overline{0}$ & 0 & $\overline{0}$ & $\begin{array}{r}24 \\
2\end{array}$ & 4,24 \\
\hline & & Rata-1 & & uruh & & $\tan$ & ja & & & & $\begin{array}{l}12 \\
20\end{array}$ & 21,38 \\
\hline
\end{tabular}

Sumber : Hasil Output SPSS 20, 2019

Berdasarkan tabel 4.5 menunjukan sebagian besar responden memilih jawaban sangat setuju yaitu sebesar 25 orang responden. Adanya data ini menunjukkan bahwa sebagian besar pegawai pada Dinas Pemadam Kebakaran Kabupaten Bone sangat mengapresiasi dengan adanya penanganan gangguan kesehatan sebagai langkah pertama bagi pegawai yang mengalami gangguan kesehatan.

\section{b. Variabel Kinerja Pegawai}

Variabel kinerja pegawai $(\mathrm{Y})$ terdiri dari 5 item yaitu, penguasaan peralatan berupa mesin dan atribut K3 yang baik dapat menghindari terjadinya kecelakaan kerja tingkat kebisingan dan getaran diusahakan agar tidak memengaruhi kinerja atau hasil kerja (Y1.1) , keselamatan dan kesehatan kerja pegawai dapat meningkatkan kinerja pegawai dalam mencapai hasil yang sesuai dengan yang ditetapkan $\left(\mathrm{Y}_{1.2}\right)$, agar tercapainya kinerja kerja pegawai yang ditetapkan maka setiap pegawai harus menerapkan ketepatan waktu dalam bekerja $\left(\mathrm{Y}_{1.3}\right)$ penerapan sistem keselamatan dan kesehatan kerja yang baik dapat membuat pegawai bekerja dengan hasil yang efektif dan efisien $\left(\mathrm{Y}_{1.4}\right)$ dan pegawai harus memiliki komitmen dalam bekerja $\left(\mathrm{Y}_{1.5}\right)$. 
Tabel 4.6

Variabel Kinerja Pegawai

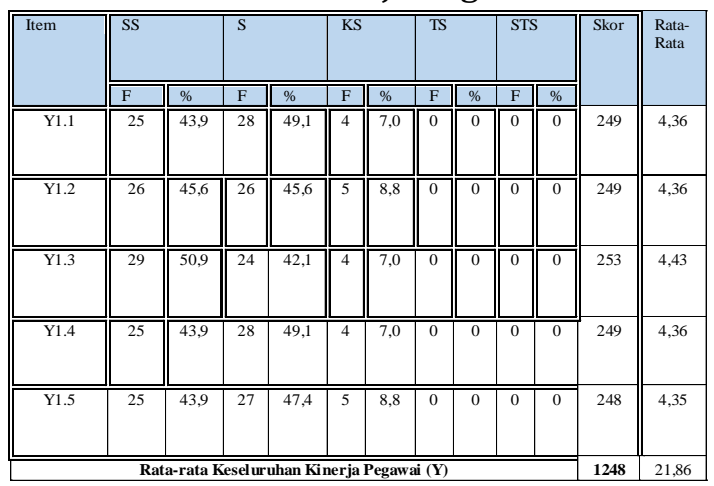

Sumber : Hasil Output SPSS 20, 2019

Berdasarkan

tabel

4.6

menunjukkan sebagian besar responden memilih jawaban sangat setuju yaitu pada item Y1.3 sebesar 29 orang responden. Adanya data ini menunjukkan bahwa sebagian besar pegawai yang ada pada Dinas Pemadam Kebakaran Kabupaten Bone memiliki argumentasi yang sama, bahwa dengan adanya penerapan sistem kesehatan dan keselamatan kerja yang baik. Hal terebut berpengaruh bagi kinerja mereka, dan tentunya ini juga berdampak pada pencapaian target yang lebih efektif.

\section{Hasil dan Olah Statistik}

a) Uji Validitas

Uji validitas adalah pengujian sejauh mana suatu ukuran yang menunjukkan tingkat-tingkat kevalidan atau kesahihan sesuatu instrument.53 Suatu item kuisioner dinyatakan valid apabila nilai $r$ hitung $>r$ tabel. Pengujian validitas dapat dilihat di bawah ini:
Tabel 4.7

Hasil Uji Validitas

\begin{tabular}{|c|c|c|c|c|}
\hline Variabel & Item & $\begin{array}{l}\mathbf{r} \\
\text { hitung }\end{array}$ & $\begin{array}{l}\mathbf{r} \\
\text { tabel }\end{array}$ & Keterangan \\
\hline \multirow{5}{*}{$\begin{array}{l}\text { Keselamatan Kerja } \\
\left(\mathrm{X}_{1}\right)\end{array}$} & 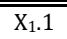 & 0,377 & 0,256 & Valid \\
\hline & $\mathrm{X}_{1.2}$ & 0,477 & $0,0,256$ & Valid \\
\hline & $\mathrm{X}_{1.3}$ & 0,420 & 0,256 & Valid \\
\hline & $\overline{X_{1} .4}$ & 0,438 & 0,256 & Valid \\
\hline & 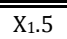 & 0,336 & 0,256 & "Valid \\
\hline \multirow{5}{*}{$\begin{array}{l}\text { Kesehatan Kerja } \\
\left(\mathrm{X}_{2}\right)\end{array}$} & 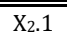 & 0,406 & 0,256 & Valid \\
\hline & $\mathrm{X}_{2} .2$ & 0,330 & 0,256 & "Valid \\
\hline & 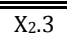 & 0,365 & 0,256 & Valid \\
\hline & $\mathrm{X}_{2.4}$ & 0,279 & 0,256 & Valid \\
\hline & 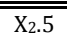 & 0,466 & 0,256 & Valid \\
\hline \multirow{5}{*}{$\begin{array}{l}\text { Kinerja } \\
\text { (Y) }\end{array}$} & 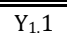 & 0,262 & 0,256 & Valid \\
\hline & 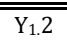 & 0,384 & 0,256 & Valid \\
\hline & $\begin{array}{l}Y_{1.3} \\
\end{array}$ & 0,597 & 0,256 & Valid \\
\hline & $\mathrm{Y}_{1.4}$ & 0,540 & 0,256 & Valid \\
\hline & 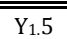 & 0,537 & 0,256 & Valid \\
\hline
\end{tabular}

Sumber : Hasil Ouput SPSS 20, 2019

Tabel 4.7 menunjukkan bahwa seluruh item pertanyaan memiliki corrected item-total correlation (r-hitung) $>$ r-tabel yaitu 0,256. Ini berarti seluruh item masing-masing yang ada dinyatakan valid.

b) Uji Reliabilitas

Uji reliabilitas dilakukan untuk menguji akurasi dan ketepatan dari pengukurannya. Instrumen reliabel bisa menggunakan batas nilai Cronbach Alpha 0,60 . Jika reliabilitas kurang dari 0,60 adalah kurang baik, sedangkan 0,70 dapat diterima dan di atas 0,80 adalah baik. Pengujian reliabilitas dapat dilihat di bawah ini. 
Tabel 4.8

Hasil Uji Reliabilitas

\begin{tabular}{|c||c||c|}
\hline Cronbach's Alpha & $\begin{array}{c}\text { N of } \\
\text { Items }\end{array}$ & Keterangan \\
\hline \hline .136 & 15 & Reliabel \\
\hline
\end{tabular}

Sumber : Hasil Output SPSS 20, 2019

Hasil uji reliabilitas pada Tabel 4.8 menunjukkan bahwa variabel mempunyai nilai Cronbach Alpha > 0,60. Jadi, dapat dikatakan semua konsep pengukur variabel dari kuisioner adalah reliable (dapat diandalkan) sehingga untuk selanjutnya item pada masing-masing variabel tersebut layak digunakan sebagai alat ukur.

\section{Teknik Analisis Data}

a) Regresi linier berganda

Digunakan untuk menganalisis Pengaruh keselamatan kerja dan kesehatan terhadap kinerja pegawai pada Dinas Pemadam Kebakaran Kabupaten Bone. Tingkat kepercayaan yang digunakan dalam analisis ini adalah $\alpha=5$

\section{Tabel 4.9}

Hasil Analisis Regresi Linear Berganda

\begin{tabular}{|c|c|c|c|c|c|}
\hline \multirow[t]{2}{*}{ Model } & \multicolumn{2}{|c|}{$\begin{array}{l}\text { Unstandardized } \\
\text { Coefficients }\end{array}$} & \multirow{2}{*}{$\begin{array}{l}\text { Standardiz } \\
\text { ed } \\
\text { Coefficient } \\
\text { s } \\
\text { Beta }\end{array}$} & \multirow[t]{2}{*}{$\mathrm{t}$} & \multirow[t]{2}{*}{ Sig. } \\
\hline & B & $\begin{array}{l}\text { Std. } \\
\text { Error }\end{array}$ & & & \\
\hline $\begin{array}{l}\text { (Constan } \\
\text { t) }\end{array}$ & 16,990 & 3,541 & & 4,798 & 000 \\
\hline $\begin{array}{l}\text { KESELA } \\
\text { MATAN } \\
\text { KERJA }\end{array}$ & 462 & 121 & ,467 & 3,828 & ,000 \\
\hline $\begin{array}{l}\text { KESEHA } \\
\text { TAN } \\
\text { KERJA }\end{array}$ & 231 & 138 & 204 & 1,677 & 099 \\
\hline
\end{tabular}

a. Dependent Variable: KINERJA PEGAWAI

Sumber : Hasil Output SPSS 20, 2019

Berdasarkan tabel 4.9 maka persamaan regresi linear berganda dapat dirumuskan sebagai berikut: $\mathrm{Y}=16,990+0,462 \mathrm{X}_{1}+0,231 \mathrm{X}_{2}$
Interprestasi dari persamaan regresi linear berganda tersebut adalah pengaruh variabel keselamatan kerja terhadap kinerja pegawai adalah positif yang artinya bahwa, setiap peningkatan dari keselamatan kerja maka akan diikuti kenaikan kinerja pegawai, yakni sebesar 0,462 satuan, pengaruh variabel kesehatan kerja tahap variabel kinerja pegawai adalah juga positif yang artinya bahwa semakin baik kesehatan kerja maka akan meningkatkan kinerja pegawai yakni sebesar 0,231 satuan.

b) Uji Hipotesis

Uji hipotesis digunakan untuk mengetahui apakah masing-masing variabel bebasnya berpengaruh positif terhadap variabel terikatnya. Apabila $\mathrm{t}$ hitung $>\mathrm{t}$ tabel maka dapat dikatakan signifikan, yaitu terdapat pengaruh antara variabel bebas yang diteliti dengan variabel terikatnya. Adapun t tabel yang diperoleh dari tabel statistic adalah sebesar 2,002. Pengujian hipotesis yang diajukan yaitu adanya pengaruh keselamatan kerja terhadap kinerja pegawai dapat diterima. Diketahui dari analisis regresi linier berganda diperoleh keterangan bahwa variabel keselamatan kerja perpengaruh positif terhadap kinerja pegawai secara signifikan.

Besarnya pengaruh variabel keselamatan kerja berpengaruh positif terhadap kinerja pegawai adalah nilai $\mathrm{t}$ hitung 3,828 > t tabel 2,002 dengan nilai signifikan yaitu $0,000<0,05$ pada tabel (4.9) hasil analisis regresi linier berganda menunjukkan bahwa variabel keselamatan kerja merupakan salah satu faktor yang memiliki pengaruh signifikan terhadap terhadap kinerja Aparatur Sipil Negara pada Dinas Pemadam Kebakaran Kabupaten Bone. Pengujian hipotesis yang diajukan yaitu adanya pengaruh kesehatan kerja terhadap kinerja pegawai 
dapat diterima. Diketahui hasil analisis linier berganda yang diperoleh keterangan bahwa variabel kesehatan kerja berpengaruh positif terhadap kinerja pegawai tetapi tidak signifikan. Besar pengaruh variabel kesehatan kerja berpengaruh positif terhadap kinerja pegawai adalah nilai $\mathrm{t}$ hitung 1,667 $<\mathrm{t}$ tabel 2,002 dengan nilai signifikasi 0.099 $>0,05$ pada tabel (4.9). hasil analisis linier berganda menunjukkan bahwa kesehatan kerja berpengaruh positif tetapi tidak signifikan terhadap kinerja Aparatur Sipil Negara.

c) Koefisien Determinasi

Koefisien Determinasi ( $\mathrm{R}$ square atau $\mathrm{R}$ kuadrad). Atau disimbolkan dengan R2 yang bermakna sebagai sumbangan pengaruh yang diberikan variabel bebas atau variabel independen (x) terhadap variabel terikat atau variabel dependen (Y). Atau dengan kata lain, nilai koefisien determinasi atau $r$ square ini berguna untuk memprediksi dan melihat seberapa besar kontribusi pengaruh yang diberikan variabel $\mathrm{x}$ secara simultan (bersama-sama) terhadap variabel $\mathrm{x}$. Adapaun tabel koefisien determinasi dapat dilihat sebagai berikut :

Tabel 4.10

Hasil Koefisien Determinasi

Model Summaryb

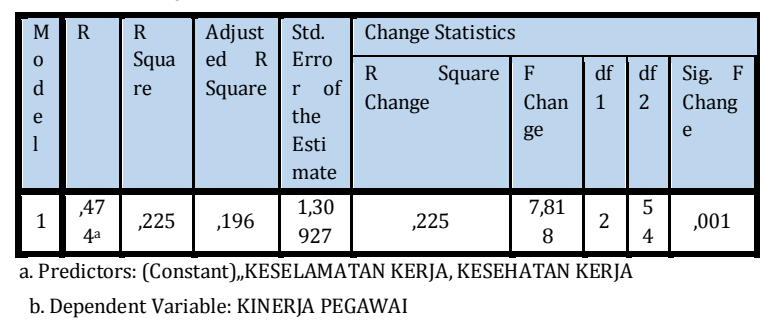

Sumber : Hasil Output SPSS 20, 2019

Berdasarkan $\quad 4.10 \quad$ koefisien korelasi (R) sebesar 0,474 hal ini menunjukkan bahwa hubungan keselamatan dan kesehatan kerja terhadap kinerja pegawai kategori nilai $\mathrm{R}$ sedangkan diketahui bahwa $\mathrm{R}$ Square memiliki nilai sebesar 0,225. Artinya variabel keselamatan dan kesehatan kerja memberikan pengaruh terhadap kinerja pegawai sebesar 22,5 \% dan sisanya $77,5 \%$ dipengaruh oleh faktor lain yang tidak diteliti.

\section{b. Pembahasan}

\section{Pengaruh Keselamatan Kerja Terhadap Kinerja Karyawan}

Pengujian hipótesis yang diajukan yaitu adanya pengaruh keselamatan kerja terhadap kinerja pegawai dapat diterima. Diketahui dari hasil analisis regresi diperoleh keterangan bahwa variabel keselamatan kerja berpengaruh positif terhadap kinerja pegawai secara signifikan. Ini berarti semakin penting keselamatan kerja berakibat pada semakin baiknya kinerja pegawainya. Hasil analisis regresi linier berganda menunjukkan bahwa variabel keselamatan kerja merupakan salah satu faktor yang memiliki pengaruh signifikan terhadap kinerja pegawai. Hasil penelitian ini mendukung hasil penelitian yang dilakukan oleh Merysa Anjani (2014), Muhammad Busyairi, ayu oktaviani (2014), Fendy Budianto (2014) variabel keselamatan kerja berpengaruh positif dan signifikan terhadap kinerja karyawan terdapat pada tabel tinjauan empiris.

\section{Pengaruh Kesehatan Kerja Terhadap Kinerja pegawai}

Pengujian hipótesis didapatkan hasil yaitu terdapat adanya pengaruh kesehatan kerja terhadap kinerja pegawai sehingga hipotesis dapat diterima. Diketahui dari hasil analisis regresi diperoleh keterangan bahwa variabel kesehatan kerja bepengaruh positif tetapi tidak signifikan terhadap kinerja pegawai. Dari hasil pengujian didapatkan hasil bahwa kesehatan kerja berpengaruh positif tetapi tidak signifikan terhadap 
kinerja pegawai. Hasil penelitian ini berbeda dengan hasil penelitian yang dilakukan oleh Merysa Anjani (2014), Karina Zain Suyono, Erwin Dyah Nawawinetu (2013), Muhammad Busyairi, ayu oktaviani (2014), Fendy Budianto (2014). dengan hasil penelitian variabel X2 kesehatan kerja berpengaruh positif dan signifikan terhadap kinerja karyawan terdapat pada tabel tinjauan empiris

\section{PENUTUP}

\section{a. Kesimpulan}

Bedasarkan hasil penelitian yang telah dilakukan untuk menguji pengaruh keselamatan dan kesehatan kerja terhadap kinerja pegawai aparatur sipil negara pada Dinas Pemadam Kebakaran Kabupaten Bone dapat disimpulkan bahwa:

1. Variabel keselamatan kerja berpengaruh positif dan signifikan terhadap kinerja pegawai Aparatur Sipil Negara pada Dinas Pemadam Kebakaran Kabupaten Bone, hal ini di tunjukkan pada nilai Unstandardized Coefficients b 0,462 dan nilai t hitung $3,828>t$ tabel 2,002 dengan taraf signifikasi sebesar $0,000<0,05$

2. Variabel Kesehatan kerja berpengaruh positif tetapi tidak signifikan terhadap kinerja pegawai Aparatur Sipil Negara pada Dinas Pemadam Kebakaran Kabupaten Bone, hal ini di tunjukkan pada nilai Unstandardized Coefficients menunjukkan 0,231 t hitung 1,677 < t tabel 2,002 dengan taraf signifikasi sebesar $0,099<0,05$

\section{b. Saran}

Berdasarkan hasil penelitian yang telah dipaparkan sebelumnya maka saran peneliti terhadap Dinas Pemadam Kebakaran Kabupaten Bone adalah Dinas Pemadam Kebakaran Kabupaten Bone lebih memperhatikan keselamatan kerja. Hal ini dibuktikan dari hasil penelitian bahwa variabel keselamatan kerja lebih berpengaruh dan signifikan pada kinerja pegawai, karena ada beberapa hal yang membahayakan keselamatan pegawai menanggulangi kebakaran terjadi, maka adanya penganangan yang lebih serius seperti pengecekan mesin dan peralatan, dan memberikan pelatiahan metode kerja yang baik pada setiap pegawai.

\section{DAFTAR PUSTAKA}

Aprianto Brian, SPHR Fonny Asriady Jacob. (2013). Pedoman Lengkap Profesional SDM Indonesia.. @ppmManajemen.ac.id: Jakarta Pusat

Fendy Budianto. 2014. Pengaruh Penerapan Program Keselamatan dan Kesehatan Kerja terhadap Komitmen Organisasional pada Karyawan bagian Produksi PR. Sumber Kencana di Bojo negoro. Agora Vol. 2 no. 1 ISSN 568-594. Http://scholar.google.co.id. diakses 26 maret 2019.

G Ukhisia, Retno As (2013)Analisis Pengaruh kesehatan dan Keselamatan Kerja terhadap Produktivitas Kerja dengan Metode Partial least Squarses. Jurnal Teknologi Pertanian Vol 14 no. 2 ISSN

113-129. Http://scholar.google.co.id. diakses 26 maret 2019.

Karina Zain Suyono, Erwin Dyah Nawawinetu. 2013. Hubungan antara Faktor Pembentuk Budaya Keselamatan Kerja dengan Savety behavior di PT DOK dan Perkapalan Surabaya Unit Hull Construction. The Indonesian journal of Occopational Satety and Health.Vol : 2 no. 1 ISSN 67-74. Http://scholar.google.co.id. diakses 26 maret 2019. 

Manullang, 2000, Dasar-dasar Manajemen, Ghalia Indonesia: Jakarta.

Marsam \& Muah. (2017). Manajemen Sumber Daya Manusia Profesional. Zifatama Publisher: Sidoarjo:

Marwansyah. (2016). Manajemen Sumber Daya ManusiaAlfabeta: Jakarta

Mas'ud, Fuad(2004),Survai Diagnosis Organisasional (Konsep Dan Aplikasi). Badan Penerbit Universitas Diponegoro: Semarang.

Mathis, R,L. \& J.H. jackson. 2006 Human Resource Mananajement: Manajemen Sumber Daya Manusia. Salemba Empat: Jakarta.

Merysa Anjani, 2014. Pengaruh Keselamatan dan Kesehatan Kerja terhadap Kinerja Karyawan Studi ada Karyawan Bagian Produksi PT. Internasional Power Motsui Operation and Maintenance Indonesia. Jurnal Adminitrasi Bisnis Vol. 9 no. 1 ISSN 192-200. Http://scholar.google.co.id. diakses 26 maret 2019.

Muhammad Busyairi, Ayu Oktaviani. 2014. Pengaruh Kesehatan Dan Keselamatan Kerja ( K3) terhadap Produktivitas Karyawan. Jurnal Teknik Industri Vol. 13 no. 2 ISSN 112-124.

Http://scholar.google.co.id. diakses 26 maret 2019.

Mulyadi. (2016). Manajemen Sumber Daya Manusia (MSDM).In Media: Jakarta.

Notoatmodjo Soekidjo.(2015). Pengembangan Sumber Daya Manusia. Rineka Cipta:Jakarta.

Proyono \& Marnis (2016). Manajemen Sumber Daya Manusia.Zifatama Publisher:Sidoarjo.
Raldo SV, Kaligis, Bonny FS, Jermias Tjakra, DRO Walangitan. 2013.Effect Implementation of Occupational Safety and Health Programs on Work Productivity . jurnal sipil statik. vol 1 no.3 ISSN 67-74 Http://scholar.google.co.id. di akses 25 April 2019.

Redjeki Sri, (2016). Keselamatan dan Kesehatan Kerja. Rekayasa sains: Jakarta selatan.

Samsuddin Harun. (2018). Kinerja Karyawan Tinjauan dari Dimensi Organisasi dan Komite Organisasi.Indonesia Pustaka: Sidoarjo.

Sugiyono, (2014). Metode Penelitian Pendidikan Pendekatan Kualitatif dan Kuantitatif dan R\&D. Alfabeta: Bandung.

Suma'mur. 2009. Hiegiene Perusahaan dan Keselamatan Kerja. CV Sagung Seto: Jakarta .

TIM K3 TF UNY.(2014). Keselamatan dan kesehatan kerja (K3). Universitas Negeri Yogyakarta: Yogyakarta.

Wahjono Sentot Imam.(2015). Manajemen Sumber Daya Manusia. Salemba Empat: Jakarta.

Wikie Yuni Christina, Lutfi Djakfar, Armau.2013.Effect OfOccoupational Safety and Health Culture On The Performace Of Contruction Projects. Jurnal studi manajemen \& organisasi. Vol. 6 No. 1 ISSN 96-110 http://scholar.google.co.id. diakses 25 april 2019.

Yani. (2012). Manajemen Sumber Daya Manusia. Mitra Wacana Media: Jakarta.

RR Anindya Puspita dan Trisha Gilang Saraswati. 2016. Analisis Sistem Antrian Kantor Imigrasi Kelas I 
Bandung Menggunakan model M/M/s (Studi Pemohon Walk - in dan Online Kantor Imigrasi Kelas I Bandung), $E$ - proceeding of Management (Online), Vol.3, No.2, (http://libraryeproceeding.telkomu niversity.ac.id/index.php/managem ent/article/view/2056, di akses 28 Januari 2018).

Siagian, P. Penelitian Operasional Teori Dan Praktek. 2006. Jakarta: Universitas Indonesia

Sugiyono. 2017. Metode Penelitian Pendidikan; Pendekatan Kuantitatif kualitatif dan R\&D Bandung: Alfabeta

Soegoto, E.S. 2007. Marketing Research: Panduan Bagi Manajer, Pemimpin Perusahaan Organisasi. Jakarta: Elex Media Komputindo 